For health promotion practitioners, local government policy makers and community organisations

April 2020

\title{
Alcohol Cultures \\ Guide: taking \\ action on risky \\ drinking cultures
}

To support use of the VicHealth

Alcohol Cultures Framework 


\section{Introduction}

This guide supports people to use the VicHealth Alcohol Cultures Framework and take action on risky drinking cultures. The guide has been developed in consultation with key stakeholders involved in delivering and evaluating alcohol culture change projects as part of the VicHealth Alcohol Culture Change Initiative 2016-2019.

The guide covers the following areas:

1. What is Alcohol Culture Change?

2. What is a social world?

3. How to design and implement a culture change project

4. Case studies: alcohol culture change projects and approaches. 


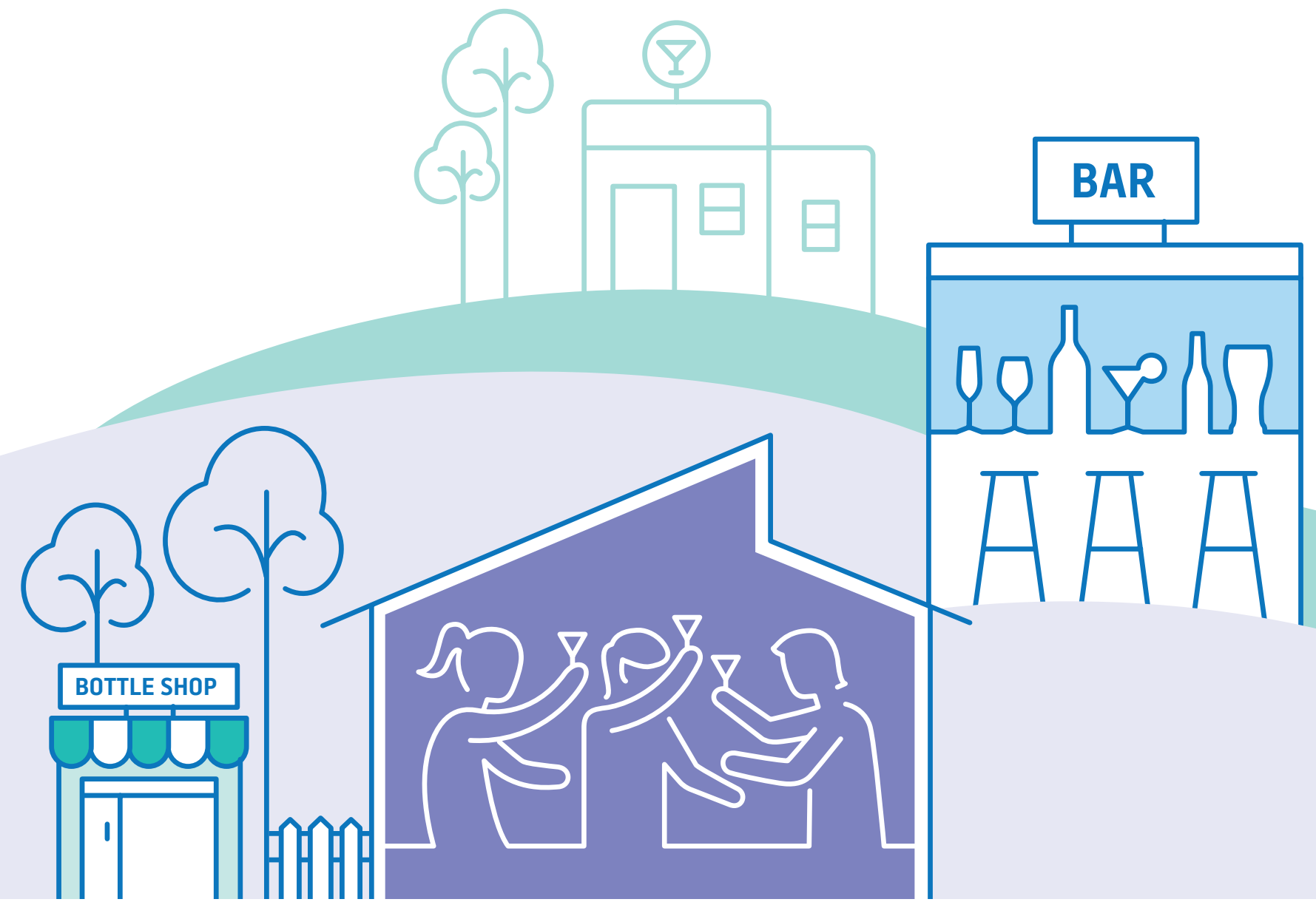

(a) VicHealth

\section{What is alcohol culture change?}

Alcohol culture change recognises that most drinking occurs within a social context (a social world) and seeks to influence this context in order to change risky drinking cultures.

An example of an alcohol culture change project might be working with a sports club or workplace to shift the physical "setting".

For example, changing whether and how alcohol is sold or the kinds of messages that are displayed; changing the interpersonal characteristics of the social world; or changing shared meanings around alcohol (e.g. seeing drinking as a way to bond with others in the group and/or celebrating drunkenness).

This is different to delivering a targeted education campaign that encourages individuals to change their drinking habits (e.g. by appealing to personal knowledge of the potentially harmful effects of drinking alcohol), or broader population efforts such as drink driving campaigns (e.g. police messages about the risk of being breathalysed).

The strengths of an alcohol culture change approach are that it:

- ensures public health efforts are relevant and effective by recognising the social conditions, contexts and the practices and routines of people's everyday lives

- targets those most in need, where risky drinking and risk of alcohol-related harm is greatest

- complements other public health efforts aimed at preventing and reducing alcohol-related harm, targeting individuals and the population as a whole. 


\section{What is a social world?}

A social world is a group of people who get together around a common interest or activity.

Members of a social world may or may not know each other, but they share social norms and practices, including expectations, about how people behave when they meet. Individuals have more than one social world.

Where there is an established drinking culture, the norms, practices and expectations are shared within the social world - and in some social worlds, there is a risky drinking culture where harm from alcohol products is common.

\section{Changing social worlds with risky drinking cultures}

Changing risky drinking cultures isn't about telling people they can't have a drink or taking someone away from a social world, it's about influencing the activities and practices that are acceptable in a social world to minimise harm from alcohol products.
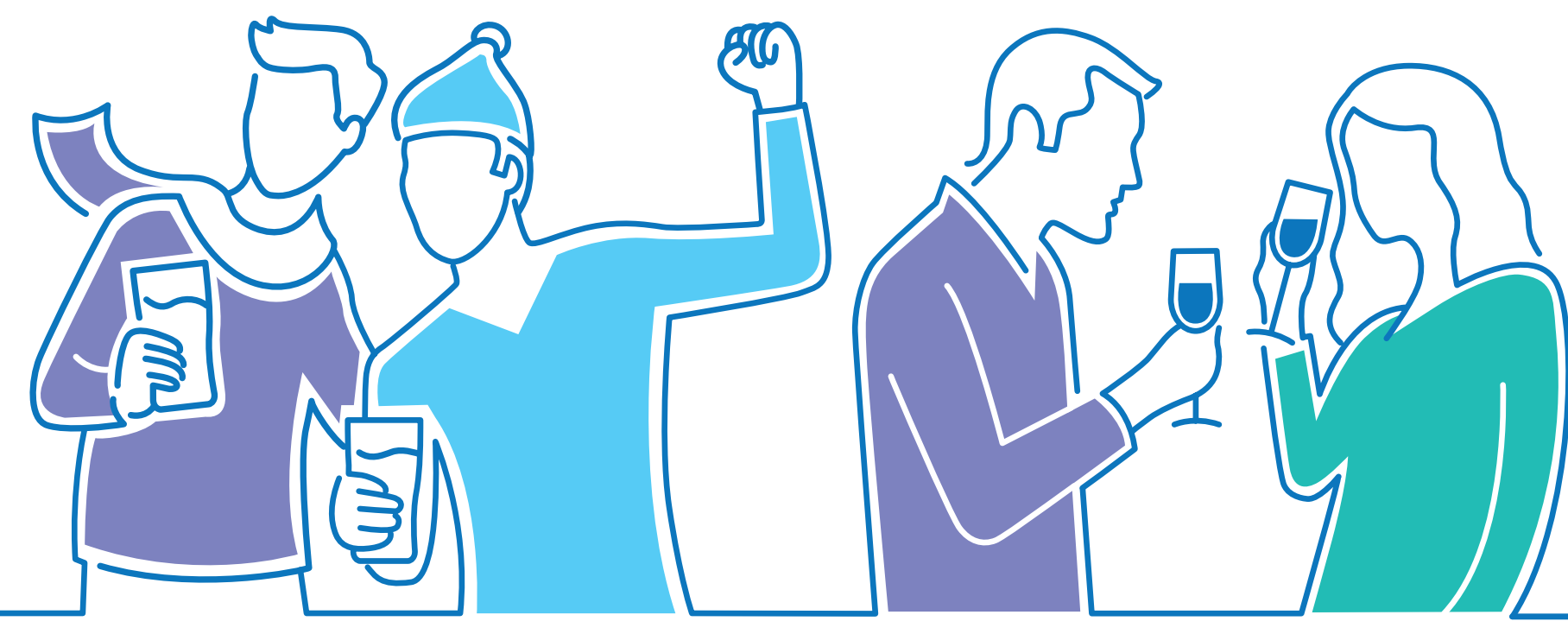

(a) VicHealth 

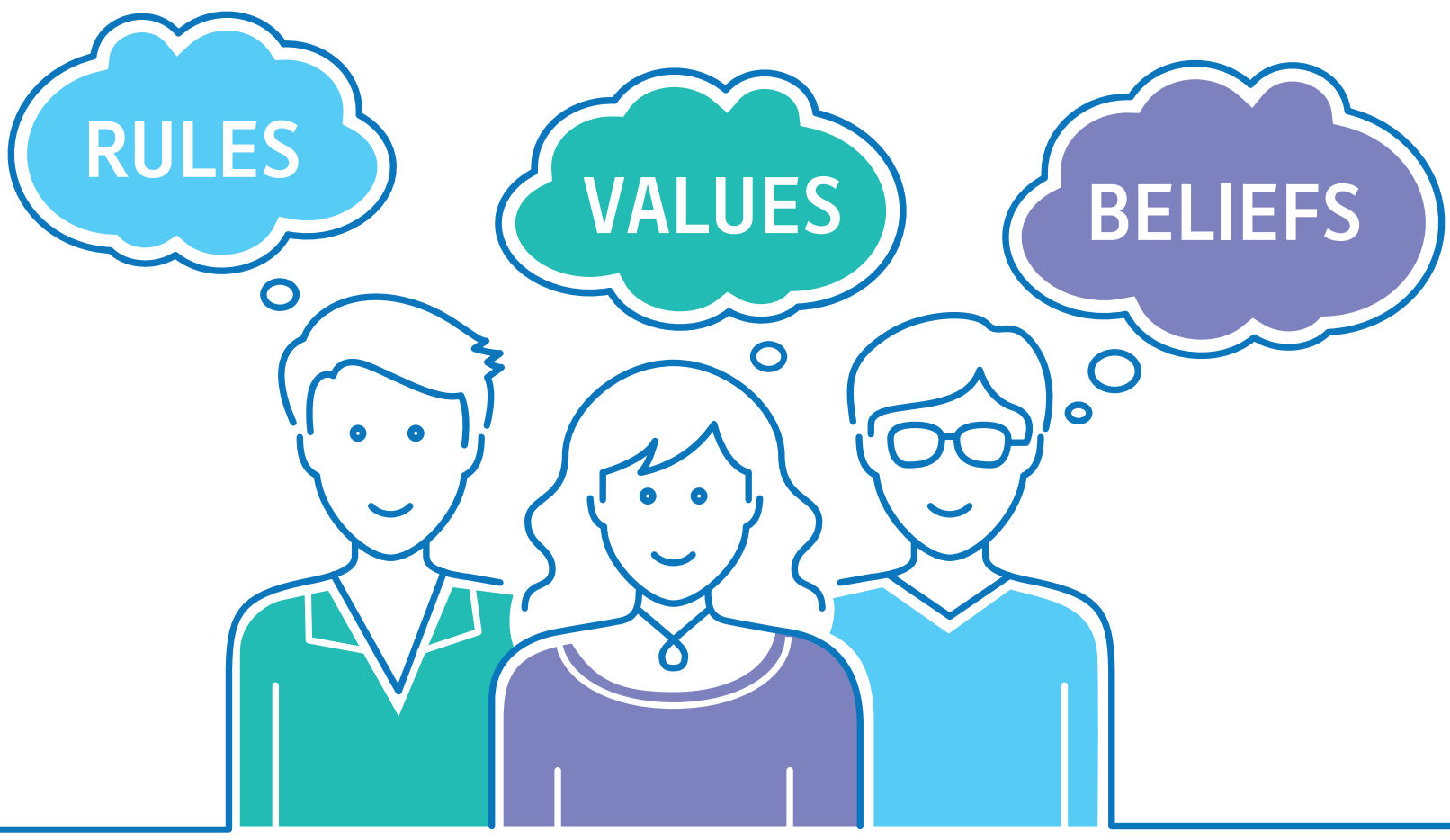

(a) VicHealth

\section{How to design and implement an alcohol culture change project}

Designing and implementing an alcohol culture change project requires considerable thought and planning to ensure the success of the project. Below are some ideas about things to consider when planning your alcohol culture change project.

\section{Project context}

Ensure your project aligns with the organisation's strategic and operational plans. This supports the rationale and potential sustainability of the project.

Ensure organisational policies and processes support alcohol culture change activities, by asking these questions:

1. Do the organisation's policies support you to implement the project?

2. Does the organisation have a culture that prevents harm from alcohol? Is it 'walking the talk'? Are leaders supportive of alcohol culture change?

3. Do existing organisational policies and processes have gaps or opportunities for improvement?

\section{Project focus}

Determine the project target group (the social world) that engages in risky drinking practices.

Use/collect strong/rigorous evidence to identify groups where risky drinking and risk of alcohol-related harm is greatest.

\section{Gain insights about the social world}

Focus on groups of people that engage in risky drinking practices, not individuals. The group may be defined by the place they gather, the things they do, or a shared activity or interest.

The focus is on changing norms about alcohol in the group, not the behaviour of individuals in isolation of the group.

Carry out the following with your target group:

- build a deep understanding of the target group using a range of methods e.g. literature review, focus groups, stakeholder consultation, survey, and local knowledge and connections

- understand how the settings, skills and shared meanings of the social world influence the way people drink

- focus on risky drinking practices in the social world and understand how these are sustained by connections to other practices (i.e. playing sport or going to work)

- identify the factors that might influence risky drinking practices such as age, gender, occupation, education, social class, ability, sexuality or ethnicity

- identify practices which discourage risky drinking or support low risk/moderate drinking. 
Consider the practices and activities that are shared by the group, by asking these questions:

1. Who are they with?

2. When do they drink?

3. Where does drinking take place? (i.e. the venue or physical environment and availability of alcohol products)

4. Why are they drinking together? (i.e. what are the shared cultural expectations, norms and understandings of drinking)

5. What social know-how or skills do members of the group need to have when they drink together? (i.e. are they expected to buy rounds, play drinking games).

\section{Internal 'buy-in'}

Determine who within your organisation needs/should know about the project and/or be involved in project development and implementation. This includes managers (and executive managers), communication/marketing staff, colleagues, councillors, other departments/divisions.

- Ensure that internal stakeholders clearly understand the rationale for the project and importance of its implementation.

- Involve key decision-makers and gate keepers at all stages of the project. This could include staff that authorise access to resources or grant permissions for social media platforms or branding.

- Develop clear strategies for engaging and communicating with key personnel within the organisation throughout all stages of the project.

\section{Involvement of stakeholders}

In addition to people within your organisation, stakeholders in the project should include organisations and individuals committed to reducing harm from alcohol e.g. partner organisations with an interest in community safety, youth or sports services, representatives of community organisations, academics, schools, local businesses, community members and key members of the target group.

\section{Role of stakeholders}

Different stakeholders have varying levels of involvement and responsibilities when contributing to a project. This may differ as the project proceeds.

It can range from occasional contributions to full project involvement. The project manager needs to manage stakeholder expectations as stakeholders may have conflicting objectives.

\section{Choosing stakeholders}

When deciding which stakeholders to involve, the project manager needs to be clear about the purpose and expectations of engagement. Questions to ask include:

1. Why are you working with a particular stakeholder?

2. What are the roles and expectations of stakeholders? For example, are they providing advice and/or representing their organisation's commitment and views? Will they be involved in some or all stages of the project; scoping, design, implementation, and evaluation? Will you be working in partnership?

3. Why does/would the stakeholder want to engage with the project? That is, what are their expectations and understanding of the project's objectives and intended outcomes?

4. What strategies can be put in place to mitigate any risks associated with engaging stakeholders?

5. How you will get early buy-in to ensure stakeholders understand alcohol culture change, are supportive, and have realistic expectations of the work?

6. If you are working across a number of organisations or in partnership, consider if communication and branding arrangements are compatible and agree these up front.

7. Will there be a formal Memorandum of Understanding (MOU), or other letter of agreement?

\section{Working with the target group}

\section{Ensure at least one member of the project team has a strong understanding of project management, implementation and evaluation.}

People who are part of the social world (the target group) are important stakeholders and to ensure the success of the project they need to be involved in the design and testing of project strategies/interventions. This includes:

- seeking champions or allies for change to drive, amplify positive social norms and model culture shifts within the target group

- working with the early adopters of change to provide insights into their experiences, and to drive change in other members of their social world

- working together with members of the social world (target group) from start to finish, to clarify the issue and develop solutions 
- inviting members of the target social world to be part of working groups

- reimbursing participants for their expertise, time and effort

- continually seeking input.

\section{If you decide to develop resources and communication campaigns, test your ideas with the target group.}

\section{Developing implementation and evaluation plans}

It's important to clearly articulate what you're planning to do and why. An implementation plan that outlines the specific actions and resources needed to deliver each step of the project includes:

- linking the project with existing resources and programs, both internally and externally

- planning for replication and sustainability from the outset
- looking for opportunities to embed alcohol culture change into organisational policies and processes to sustain and scale efforts over the long term

- using an evaluation plan to capture the rationale for your project and linking your actions to the intended consequences of your project. Your evaluation plans should outline how you'll know if you have achieved what you intended - in terms of what you do (process evaluation), who it reaches and the intended impact.

When designing your alcohol culture change project aim to:

- be realistic about what can be achieved

- ensure short- and medium-term measures of success relate to changes in group norms and practices, not alcohol use and harm

- document project methods and processes, so others can replicate the most promising components

- share learnings with other organisations.

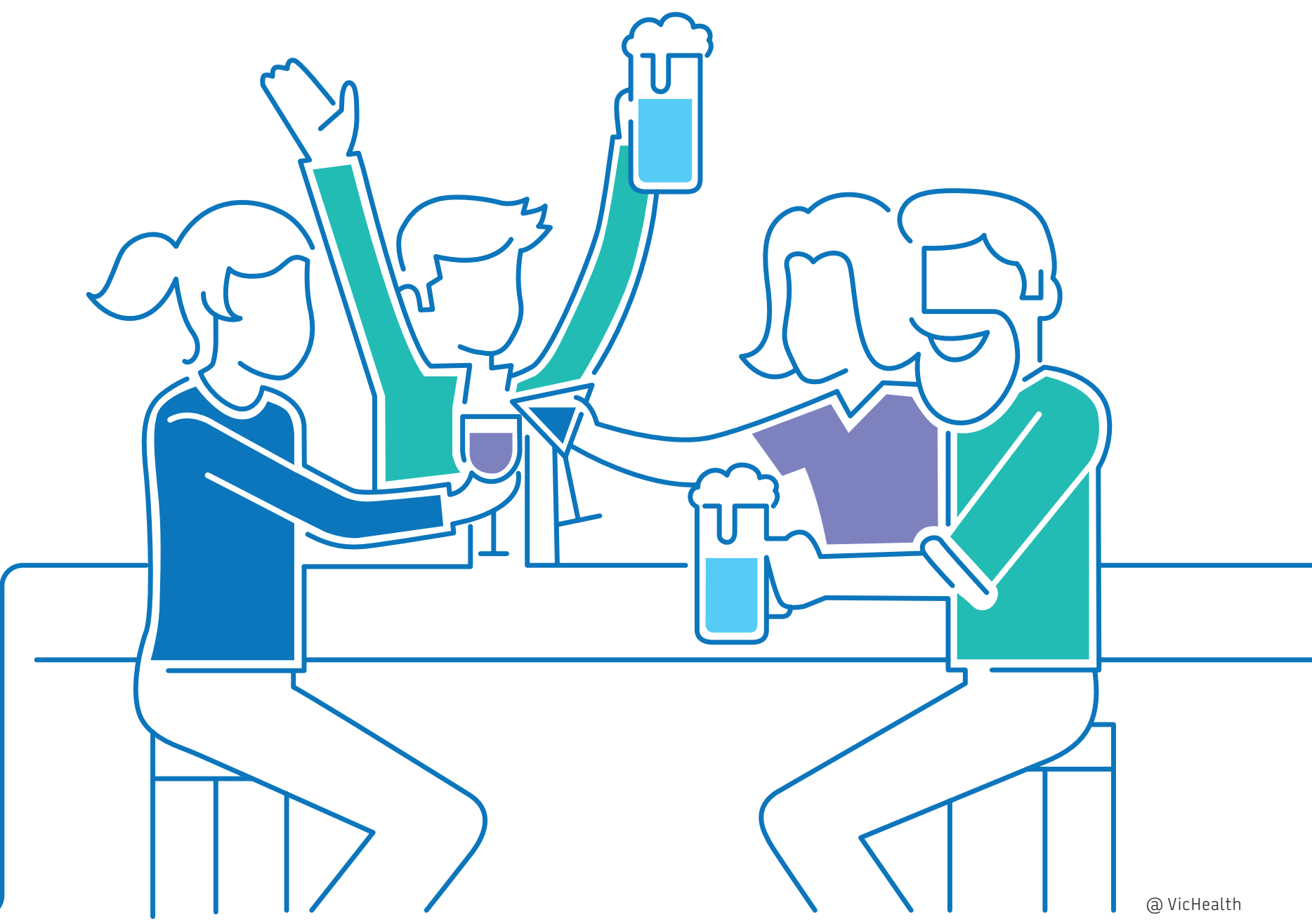




\section{Alcohol culture change project case studies}

The purpose of these case studies is to showcase some of the diverse approaches to implementing an alcohol culture change project.

The case studies provide an overview of the project goal, the target social world and the key project activities.

These projects provide useful examples to potential funding applicants to obtain ideas about what works when developing an alcohol culture change project.

\section{CASE STUDY 1}

\section{Co-design case study: Youth Action Against Risky Drinking (YAARD)}

The Youth Action against Risky Drinking project focused on changing the risky drinking culture among the social world of disengaged young people in Whittlesea.

The City of Whittlesea worked with young people from the target group to co-design a project that created a different narrative about how to connect and have fun without alcohol.

\section{Co-design actively involves all stakeholders in the project design process to help ensure the result meets their needs and is usable. \\ Co-design is sometimes described as participatory design or collaborative design.}

A social media campaign using Snapchat fostered authentic conversations among members of the social world about the positive ways in which friendship protects young people from risky drinking.

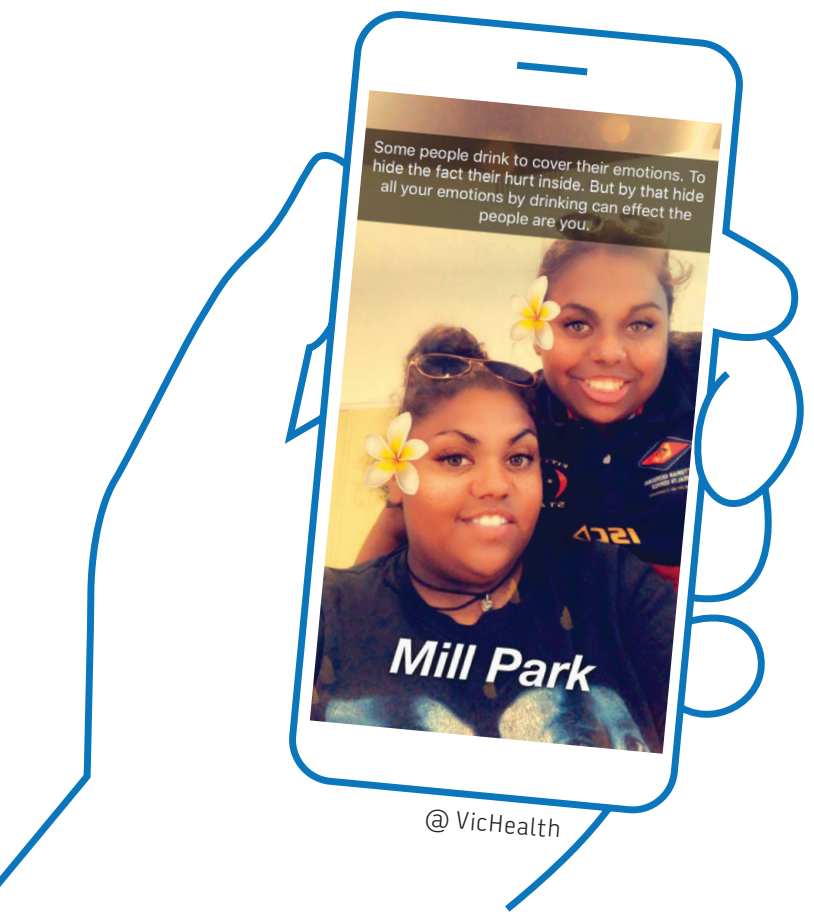

Online call for snaps from YARD project

\section{Background}

Young people in Whittlesea experience significant risk factors for alcohol harm, including high rates of disengagement, high rates of couch surfing, social isolation, limited recreation opportunities, and, for a growing number, lack of parental role models.

\section{Target social world}

Young people aged 14 to 18 years, disengaged or at risk of becoming disengaged from study, training or work.

\section{Goal}

The project aimed to reduce risky drinking among the target social world by stimulating a new conversation that focused on connection with friends and having fun without using alcohol.

\section{Project activities}

Key activities of the YAARD project were:

- a 'social lab' where a group of 15 young people worked with City of Whittlesea staff for 18 months to develop and implement the project.

- a social media campaign to encourage development of different shared meanings around alcohol use.

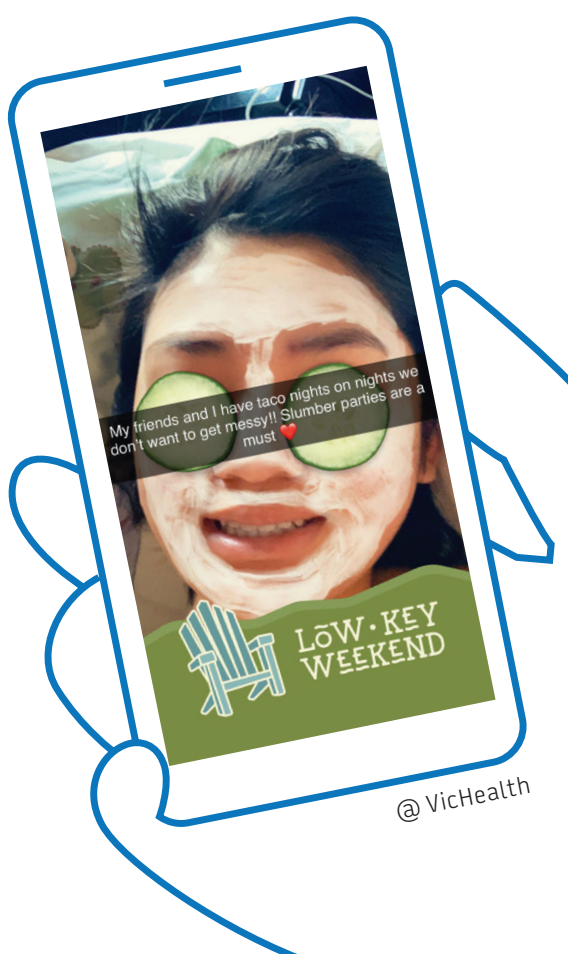




\section{The social lab}

The social lab was used as a mechanism to:

- understand drivers for alcohol culture change amongst young people

- codesign the key activities of the alcohol culture change project

- design messaging or the social media campaign.

The participants received orientation and training and upon completion received a certificate that recorded their skills and experience from the project to assist them with applying for work. c6

We removed ourselves as the mouthpiece and treated young people as the experts to come up with solutions. We needed the voice of young people to understand what is relevant and meaningful in their lives. No one understands their social world as well as they do."

YAARD Project Officer

\section{Social media campaign}

The social media campaign targeted young people in the City of Whittlesea, providing messaging that builds on social norms around trust and friendship to increase safety on a night out. Using the social media platform, SnapChat, young people talked about their own values, views and experiences.

We discovered that alcohol is an important part of young peoples' lives, in terms of creating friendship networks, socialising and becoming an adult; so, we couldn't create a "say no" campaign, as it just wouldn't work. We needed a campaign around connection with friends and having fun without using alcohol.”

YAARD Project Officer

The platform allowed the group to have conversations with their peers, about connecting with friends, easing loneliness and having fun without using alcohol.
The conversation was moderated and had systems in place to protect young people and their anonymity.

A partnership with Youth Support and Advocacy Service (YSAS) was critical for ensuring the campaign aligned with best practice harm minimisation approaches for young people.

Management of the social media platform by YSAS was critical for overcoming some challenges of using social media.

A software platform (Mish Guru) was used to capture, save, moderate and publish content on Snapchat, as well as a tool for measuring and reporting.

The platform was also important for testing different concepts and providing feedback on what types of content performs the best to increase engagement.

The ongoing and instant feedback was used to tailor future messaging and worked well alongside a co-design approach.

\section{More information}

For more information about the YAARD project, go to: www.vichealth.vic.gov.au/our-work/health-promotion-in-action/going-to-yard To find out more about co-designing with young people, go to: www.vichealth.vic.gov.au/media-and-resources/publications/co-design To read the 2017 VicHealth Letter on how co-design delivers agency, advocacy and real-world impact, go to: www.vichealth.vic.gov.au/ letter/articles/vh-letter-45-co-design
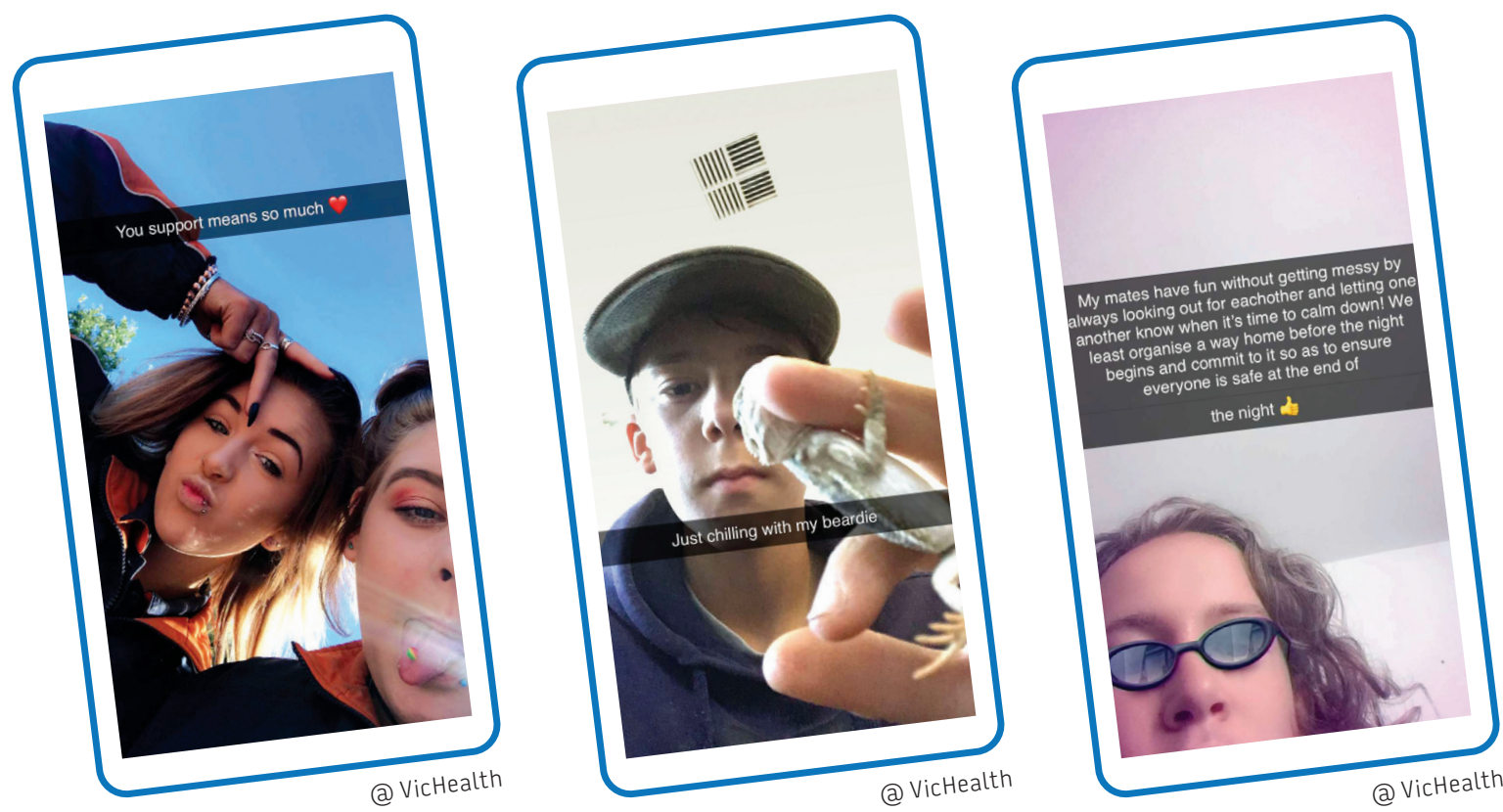


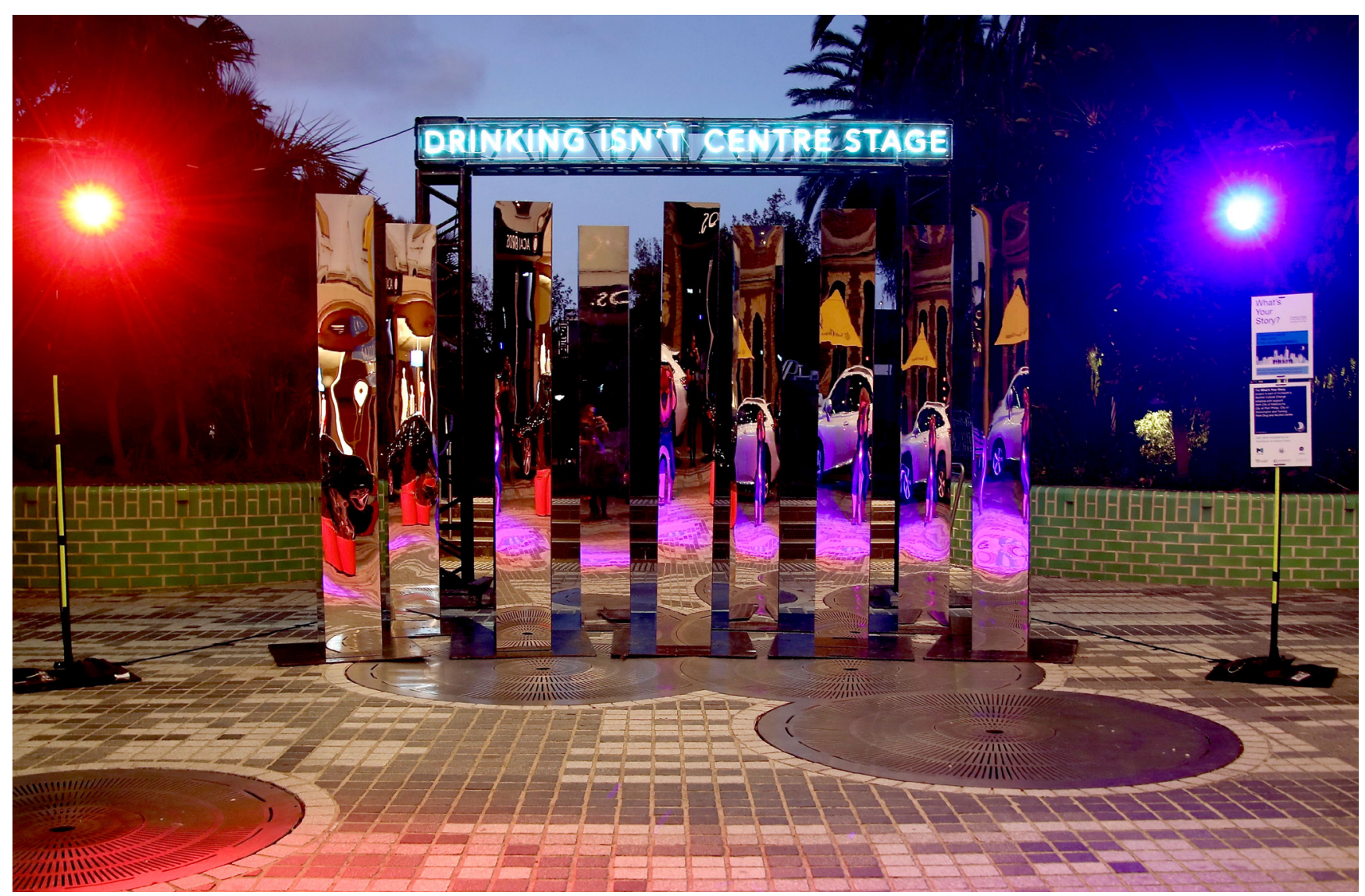

Art installation: Drinking Isn’t Centre Stage

(a) VicHealth

\section{CASE STUDY 2}

\section{Storytelling case study: What's Your Story?}

The What's Your Story project focused on shifting the risky drinking culture among young adults in the settings of late-night entertainment precincts in Port Phillip, Melbourne and Stonnington.

The project collected stories from young adults to gather insights about their experience of drinking cultures.

Stories that reflected positive social norms regarding alcohol consumption were shared using public art installations to disrupt existing norms and cultivate new ones around connecting and having fun without alcohol.

\section{What is storytelling?}

Developed and used purposefully, storytelling can engage people on social and health issues, contribute to inclusion and connection, build confidence, and bring about change.

Storytelling and the use of narrative can shift social norms and is an effective tool for health promotion and education.

\section{Background}

The three municipalities have a large number of licensed premises and experience an influx of people coming into the municipalities every weekend.

Approximately 350,000 young adults visit the areas every Friday and Saturday night, and rates of drinking and alcoholrelated harms are high.

\section{Target social world}

Young adults aged 18 to 24 years who go to late night entertainment precincts in City of Port Phillip (St Kilda), City of Melbourne (Central Business District) and City of Stonnington (Chapel Street).

\section{Goals}

The project's goal was to improve the drinking culture among young adults aged 18 to 24 years old who visit late night entertainment precincts in the Port Phillip, Melbourne and Stonnington municipalities.

The project aimed to positively influence social environments to support reduced consumption and occurrences of drinking.

They sought to do this by shifting the formal rules, social norms, attitudes, and beliefs around what is and isn't socially acceptable for a group of people, before, during and after drinking.

\section{Project activities}

The What's Your Story project used storytelling as a mechanism for shifting alcohol culture and was designed around the importance of peers and positive peer influences for young adults.

The project used young adults' stories and own accounts to facilitate culture change. The project strategies included:

- collecting stories

- sharing stories. 


\section{Collecting stories}

Stories were collected to inform research and gain insight into the experiences of young people's alcohol culture in late night entertainment precincts.

\section{“6}

The StoryPod video booth created a safe, interesting and engaging way of collecting young peoples' stories about late night culture - it was fun and a bit different."

What's Your Story? Project Officer

StoryPod video booths were used to collect and record stories. People entered the booth alone or with their friends and responded to one or two of the questions that appeared on the screen:

- tell us the story about one of your most memorable nights out and why it stands out to you

- tell us the story about how nights in Melbourne have changed for you.

The content of the stories was considered by Story Selection Panels that included young adults. A number of key themes were identified through this process including, the importance of connecting with friends and meeting new people; alcohol was not the focus of socialising.

\section{Sharing stories on social media}

Stories reflecting positive social norms regarding alcohol consumption were shared via social media and as public art installations in the physical setting (late-night precincts).

The aim of these stories was to increase the target group's engagement with positive messages through the stories, stimulate reflection on drinking practices, norms and culture, and create a positive, alternative narrative about having a night out.
(6)

We shared the stories of young adults with the group, to increase engagement and the legitimacy of the project, and help reduce the feeling of messages being imposed/ pushed. We used their words and with as little editing as possible, to preserve their experience and its complexity and nuance."

What's Your Story? Project Officer

The three public art pieces focused on the following messages: Savour It, Remember It, Music Is All I Need, and Drinking Isn't Centre Stage.

\section{Resources}

National Storytelling Network, What Is Storytelling? available at https://storynet.org/what-is-storytelling/

Newkirk, C. and Solomon, J., 2017, Using storytelling to promote health, Michigan State University, available at: www.canr.msu.edu/news/using_storytelling_to_promote_health

Gubrium, A., 2009, Digital Storytelling: An Emergent Method for Health Promotion Research and Practice, Health Promotion Practice, $10(2): 186-91$.

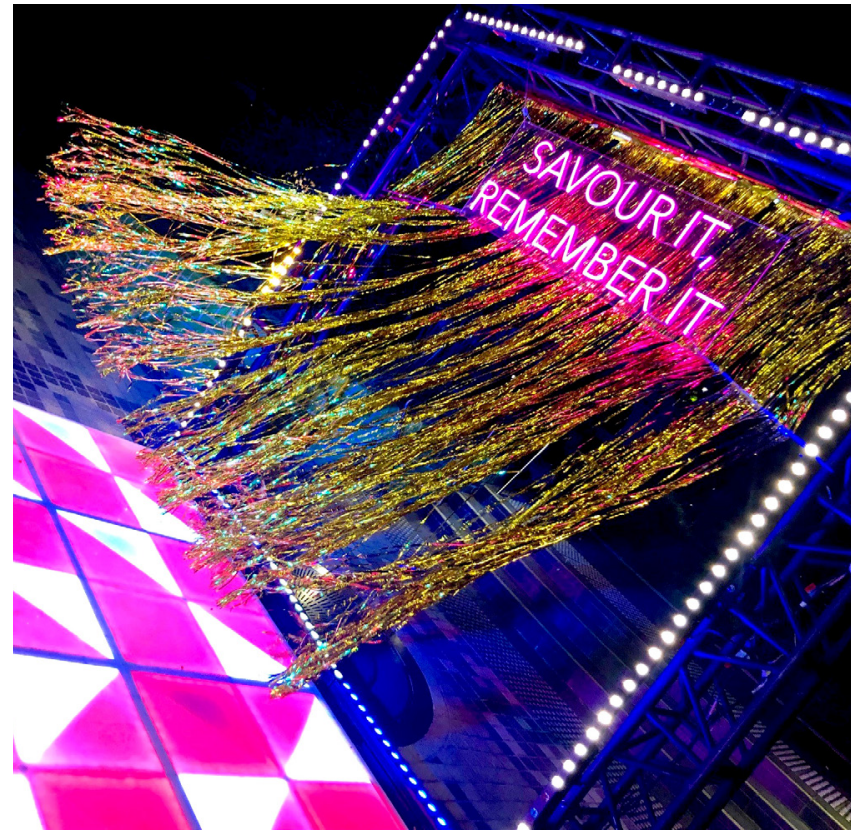

Art installation: Savour It, Remember It

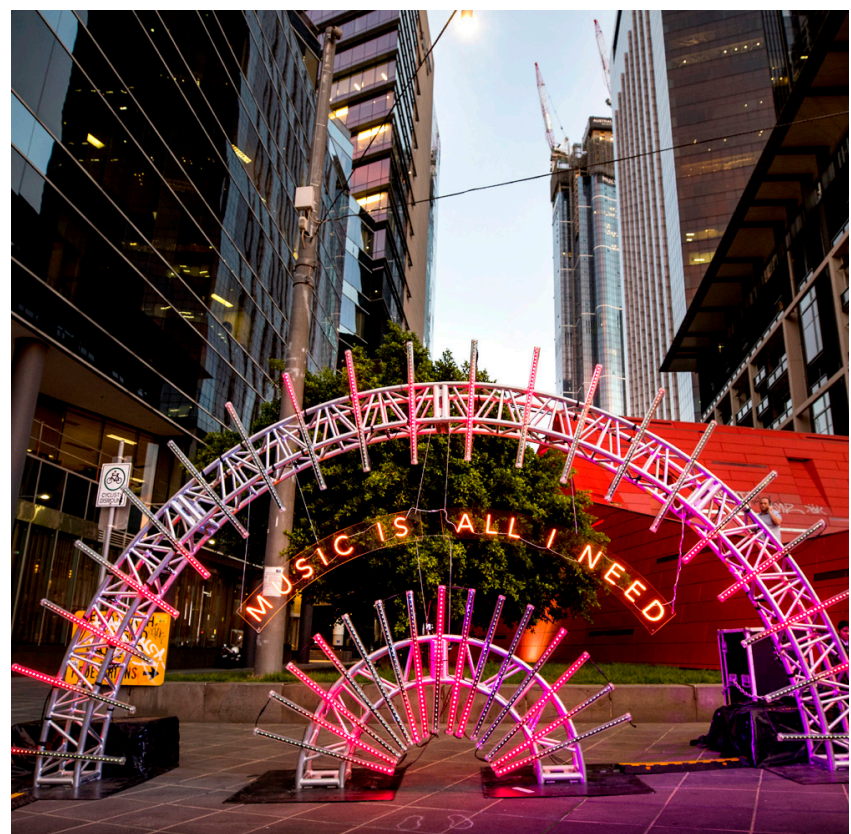

Art installation: Music Is All I Need (a) VicHealth 


\section{CASE STUDY 3}

\section{Local area case study: Youth C.A.N. (Changing Alcohol Norms)}

The Youth C.A.N. project focused on changing the risky drinking culture among young people in the rural area of Horsham. The project used a comprehensive local area approach to take action on risky drinking cultures.

It was an integrated, multifaceted project that worked with young people, parents and families, and the community to foster alcohol culture change in rural Victoria.

\section{What is a local area approach?}

Local area approaches bring together multiple stakeholders to deliver a holistic and integrated approach that addresses the issues of a local area.

\section{Background}

Drinking is common in rural communities and high-risk drinking is a serious issue for young people. Young people in the rural area of Horsham experience significant risk factors for alcohol harm, including limited recreation opportunities. There are approximately 1,735 young people aged $12-18$ years in Horsham.

\section{Target social world}

Young people aged 12-18 years living, attending school and working within a rural environment.

\section{Goals}

Change the risky drinking culture among young people in the rural area of Horsham by shifting physical settings and influencing the activities and interactions in their social world.

\section{Project activities}

The project used a local area approach working with community, parents, families and young people.

\section{(4)}

We embraced a holistic approach - as we couldn't target youth in isolation of the broader social context, and the family and community are so influential and important for sustaining effort over time."

Youth C.A.N. Project Officer

\section{Community}

The project focused on building partnerships and alliances with local agencies and implementing community awareness raising activities.

The awareness raising included: Youth CAN marketing and promotional videos, community billboards, local cinema and social media.

\begin{abstract}
af
We had good local support from local organisations - that's a benefit of a small town, everyone wants to be involved. Our partnerships helped us to deliver an integrated project that saturated the local market. People recognised the brand - they saw the ads in the cinema, went to an information night, and experienced the school curriculum. People knew what we were doing and why." Youth C.A.N. Project Officer
\end{abstract}

\section{Parents and families}

The focus of the parent and family activities was to improve their understanding of the effects of supplying alcohol, the shortterm and long-term impacts of alcohol use for 12-18-year-olds and provide channels for communication with young people and parents around these issues. Parents were provided with a number of opportunities to participate in the project, including:

- a parent network Facebook page and support group

- theatre, art and music-based education led by young people and presented to parents

- information nights and newsletters.

\section{Young people}

Young people in rural areas have limited options for entertainment and often turn to alcohol to alleviate boredom and connect with peers. Youth C.A.N. focused on providing a range of alternative activities for young people to counter the current culture of risky drinking. Events were alcohol-free with clear messages regarding alcohol culture, and young people led project activities and guided the project through a Youth Advisory Group.

Other strategies included development of a youth-led social marketing campaign and a Youth CAN brand including: logo, T-shirts, posters, information brochures and partnering with two schools to consolidate alcohol education curriculum via the rollout of Climate Schools.

af

We showed young people that it's possible to have fun without alcohol by hosting a range of events including a Colour War, a Three on Three basketball event, a Fun Night In and Amazing Race. Our Youth Advisory Group were instrumental in planning these events and making sure they were fun and focused on activities that young people enjoyed."

Youth C.A.N. Project Officer 


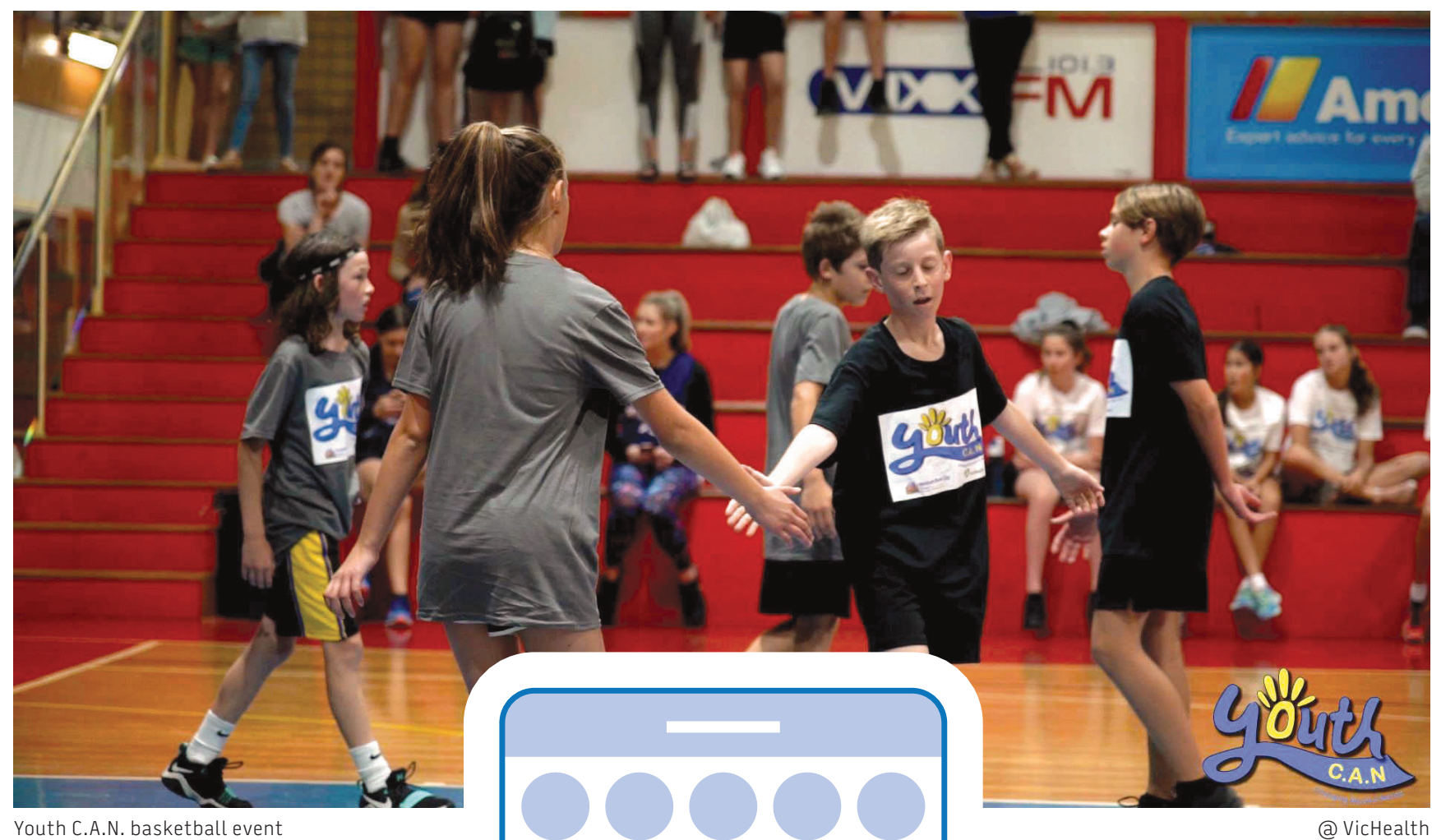

Youth C.A.N. basketball event
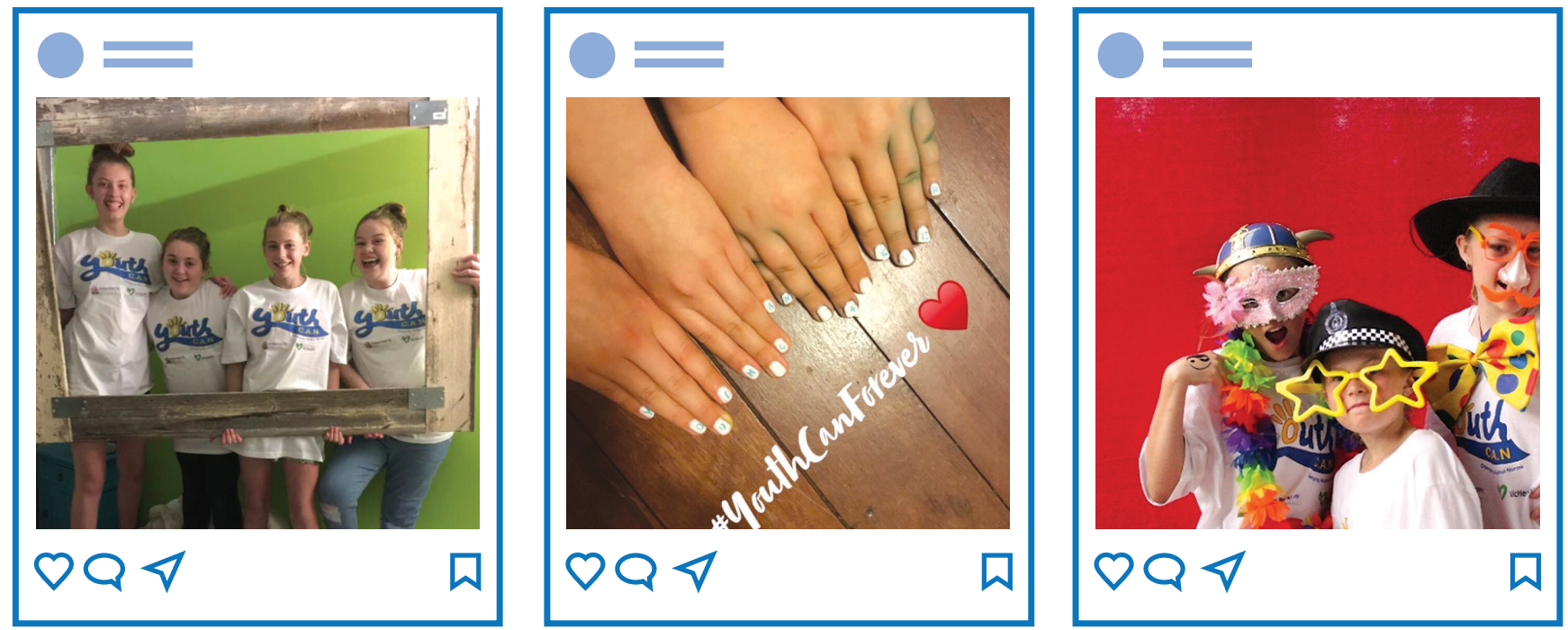

Social media images from youth-led campaign

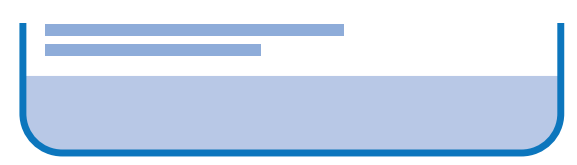

(a) VicHealth

\section{Local council}

Horsham Rural City Council took a number of steps to ensure that internal policies and processes supported alcohol culture change and established a Youth Strategy, a Youth
Leadership Group and employed a youth worker role to support young people in the future - with a focus on alcohol culture change.

\section{Resources}

Tasmanian Government, 2012, Place-Based Approaches to Health and Wellbeing Issues Paper, Department of Health and Human Services.

HealthWest Partnership, 2017, Place-based Initiatives in the West: Highlighting Promising Practice, available at: http://healthwest.org.au/events-and-networks/networks/health-promotion-prevention/place-based-initiatives-in-the-west/ 


\title{
Acknowledgements
}

VicHealth thanks everyone involved in the Alcohol Culture Change Initiative 2016-2019, particularly the following organisations who contributed to the development of this guide:

- Youth Action against Risky Drinking (YAARD) project - led by the City of Whittlesea

- What's Your Story project - led by the City of Port Phillip, City of Melbourne and The City of Stonnington

- Youth C.A.N. project - led by the Horsham Rural City Council

- YSAS Bendigo

- Monash University and Turning Point

- Humankind Enterprises

- Clear Horizons

- Federation University Australia

- Australian Institute for Primary Care and Ageing, La Trobe University

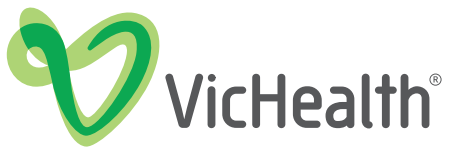

\author{
Victorian Health Promotion Foundation \\ PO Box 154 Carlton South \\ Victoria 3053 Australia \\ T+61396671333 F+61396671375 \\ vichealth@vichealth.vic.gov.au \\ vichealth.vic.gov.au \\ twitter.com/vichealth \\ facebook.com/vichealth
}

VicHealth is committed to health equity, which means levelling the playing field between people who can easily access good health and people who face barriers, to achieve the highest level of health for everyone.

VicHealth acknowledges the support of the Victorian Government.

(c) VicHealth 2020

May 2020

https://doi.org/10.37309/2020.AL817

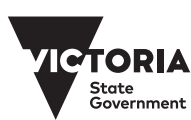

VicHealth acknowledges the Traditional Custodians of the land. We pay our respects to all Elders past, present and future. 